\title{
SERVICE GUARANTEE AS A RECOVERY STRATEGY: THE IMPACT OF GUARANTEE TERMS ON PERCEIVED JUSTICE AND FIRM MOTIVES
}

\author{
Benedetta Crisafulli and Jaywant Singh*
}

This is a pre-publication accepted manuscript of the paper. For published version please visit http://www.emeraldinsight.com/journal/josm

*Corresponding Author: Dr Jaywant Singh Email: J.Singh@kingston.ac.uk 


\begin{abstract}
Purpose - When a service fails, the guarantee policy of the firm can be employed as a recovery strategy. The terms of the guarantee determine the amount of payout and the ease of invoking the policy. The guarantee terms can, therefore, influence customer perceptions of recovery fairness and inferences about the firm's intentions in providing fair recovery. The study examines the impact of guarantee terms on customer perceptions of justice, motive attributions and repatronage intentions.
\end{abstract}

Design/methodology/approach - A between-subjects experiment was conducted in parcel delivery services.

Findings - Customer perceptions of justice vary across guarantee payout levels. Payout in the form of a discount does not restore justice perceptions, and leads to inferences that the firm offered the guarantee to maximise its profits. Conversely, full refund restores justice. Full refund plus discount is perceived as undeserved, and does not enhance justice perceptions. A moderately easy-to-invoke guarantee is perceived as fair, when it includes full refund. Inferences of negative firm's motives, however, diminish perceived fairness of easy-to-invoke guarantees.

Research limitations/implications - Future research could examine the interaction of guarantee scope with payout and ease of invocation, and how types of motives differentially impact justice perceptions.

Practical implications - Full refund can enhance justice perceptions, whereas discount is perceived as unfair. Firms should offer full refund as guarantee payout, but refrain from offering a discount. Flexibility should be embedded in guarantee invocation procedures.

Originality/value - This study demonstrates that service guarantees employed as recovery strategies signal justice and the firm's motives.

Keywords: Service recovery, Guarantee, Justice, Signaling theory, Inferred motive Article Classification: Research paper 


\section{Introduction}

The delivery of fair service recovery is crucial for restoring customer satisfaction and for encouraging repatronage following a service failure. Fair service recovery can be provided through organisational efforts, such as a compensation that offsets costs incurred by the customer, a timely resolution of the failure, and polite interpersonal treatment (e.g., Blodgett et al., 1997; Roschk and Kaiser, 2013; Smith et al., 1999; Tax et al., 1998). Although employees are instrumental in delivering recovery, organisational policies such as service guarantees, can pose a constraint to employee efforts and, in turn, influence customer perceptions of recovery fairness. For example, a customer may perceive recovery as unfair if the compensation for a delivery lost in the post does not at least cover for the cost of the service, or it is lower than the level set in the policy.

Service guarantees are frequently used by companies across sectors, such as hospitality, banking and professional services (e.g., Co-operative Bank's guarantee on customer service, Royal Mail's guarantee on delivery services). The prevalence of service guarantees has spurred conceptual and empirical studies examining the characteristics of service guarantees and the impact of these policies on consumer perceptions and behaviour. In this regard, Hart (1988) proposed the precepts of service guarantee policies, whilst Ostrom and Iacobucci (1998) investigated the role of service guarantees in shaping customer satisfaction and quality perceptions. Following on the above studies, several other issues relating to service guarantees have been examined, for instance, the influence of guarantees on customer preferences (McDougall et al., 1998) and perceptions of risk (Wirtz and Kum, 2001; Wirtz et al., 2000), service guarantee as a signaling mechanism (McCollough and Gremler, 2004), the impact of guarantees on customer cheating intentions (Wirtz and Kum, 2004), customer choice of the service provider (Wu et al., 2012), and purchase decisions (Jin and He, 2013). Despite the above advances, little empirical research has addressed how a 
service guarantee functions in a recovery context, and the impact of this policy on customer perceptions of recovery fairness.

The abovementioned paucity of research is surprising, given that guarantee policies are often invoked when a service fails. Moreover, designing and employing service guarantees is crucial for effective service management, especially in a recovery context. This viewpoint is shared by a number of researchers who contend that service guarantees represent an important, yet underestimated, recovery method, and call for research investigating the role of service guarantees in a recovery context (e.g., Berman and Mathur, 2014; BjörlinLidén and Edvardsson, 2003; Björlin-Lidén and Skålén, 2003; Callan and Moore, 1998; Hogreve and Gremler, 2009). In a conceptual study, Kandampully and Butler (2001) suggest that recovery implemented through service guarantees can reduce negative word of mouth. Further, Björlin-Lidén and Edvardsson (2003) and Björlin-Lidén and Skålén (2003) note that customers are concerned about the fairness of service guarantees and are suspicious of guarantee policies introduced in an effort to increase customer acquisition rates. However, the above studies do not examine customer perceptions of fairness and inferences about the firm's motives for introducing this guarantee, when this policy is implemented as a recovery strategy.

In a recent study, Van Vaerenberg et al. (2014) investigate how employee recovery efforts shape customer intentions towards invoking service guarantees. In the above study, service recovery and guarantees are treated as two distinct strategies and customer perceptions of justice are not examined. McQuilken et al. (2013), on the other hand, consider customer perceptions of justice related to the payout set in guarantee policies and employee behaviour, however the study does not account for customers' perceived justice towards the guarantee invocation processes. Along with guarantee payout, the invocation process 
represents an important dimension of the service guarantee policy, as pointed out by Hart (1988), and more recently by Berman and Mathur (2014).

In practice, through service guarantees, a company pledges compensation and lays down the procedures for claiming the compensation in the event of service failure (i.e. guarantee terms). These two guarantee terms, in turn, signal the firm's fairness in attempting recovery, and the firm's intentions for offering the policy. The signaling effect of guarantee terms can be seen as consistent with the well-established Signaling Theory (Spence, 1973, 1974, 2002). Prior research suggests that, in their role of signals, service guarantees convey information about the quality attributes of the service (e.g., Chen et al., 2009; Wirtz and Kum, 2001; Wirtz et al., 2000) and the firm's intentions (e.g., McCollough and Gremler, 1999). The effects of service guarantees as signals of justice in a service recovery context, however, have not yet been examined.

Further, customers evaluate the information signaled by the guarantee terms, and they draw inferences about the firm's motives for offering the policy. For example, Kukar-Kinney et al. (2007) suggest that customers infer the firm's motives from the specific terms set in the policy, which in turn influence justice perceptions. Such inferences represent attributions for the intentions or motives underlying the firm's actions, termed 'inferred motive' (Campbell, 1999). Based on the valence of inferred motives (positive or negative), customers form perceptions as to whether the guarantee terms are fair or unfair. For instance, when receiving small guarantee payout in the form of a discount rather than full refund, customers may view the firm as pursuing its own interests of profits (negative motive), rather than serving the customer interests (positive motive). In such instances, customers may feel treated unfairly. Perceptions of unfairness may in turn lower intentions to repatronize the firm. Extant service recovery research has so far overlooked inferred motive, despite the relevance of this 
attribution in explaining customers' cognitive processes of evaluating guarantee policies and concurring justice perceptions.

Seeking to address the above research gaps, this study investigates customer perceptions of justice and inferences of motive when service guarantees are employed as recovery strategies. The study sets two objectives, a) to examine how two widely-practised terms of service guarantees, namely guarantee payout (the policy compensation) and the ease of the policy invocation process (ease of invocation), signal justice rendered by the firm in handling service failures and the firm's motives, and b) to investigate how customer inferences of motive contribute to explaining customer perceptions of justice and consequent repatronage intentions.

The present study offers important contributions to theory. The findings demonstrate that service guarantees can be employed as recovery strategies. Specifically, the terms of these policies signal the firm's fairness and trigger customer inferences about the firm's motives (i.e. inferred motive). The concept of inferred motive helps in explaining the cognitive process underlying customer evaluation of service guarantees and the formation of justice perceptions in a recovery context. Notably, the study establishes that the interface between justice, signaling and attribution theories provides a useful theoretical framework for understanding customer perceptions of fairness when service guarantees are employed as recovery strategies. The findings offer practical implications on how to design optimal service guarantees, and how to leverage these policies as signals of fairness and of the firm's motives in a recovery context.

\section{Theoretical background and hypotheses development}

\subsection{Perceptions of justice in service recovery}


The concept of justice (or fairness) has long been studied in the fields of social psychology and sociology. In social psychology, the Justice Theory was first espoused by Homans (1961). Here, justice is defined as an evaluative judgment of a person's treatment, which is perceived to be fair or just when 'it corresponds to some standard or criterion of what is morally right' (Furby, 1986, p.153). In services research, scholars concur on the relevance of perceived justice in explaining customer evaluations of recovery efforts delivered by employees (e.g., Chebat and Slusarczyk, 2005; Choi and Choi, 2014; del RíoLanza et al., 2009; Schoefer and Diamantopoulos, 2008; Smith et al., 1999; Tax et al., 1998). In this domain, justice is conceptualised as consisting of three dimensions - distributive, procedural and interactional.

Distributive justice is explained by social exchange and equity theories (Adams, 1965; Blau, 1964), and it entails perceptions of receiving fairly allocated resources or outcomes. In a recovery context, customers perceive distributive justice when the benefits resulting from recovery outcomes (e.g., refund, discount, apology) outweigh the sacrifices incurred by the customer (e.g., time and effort of lodging a complaint). Procedural justice relates to perceptions that the processes followed in delivering outcomes are fair (Thibaut and Walker, 1975). In a recovery context, procedural justice results when recovery processes are timely (Karatepe, 2006) and flexible (del Río-Lanza et al., 2009). Interactional justice entails perceptions that the manner in which outcomes are communicated is fair (Bies and Moag, 1986). Customers perceive interactional justice when service employees show politeness and empathy (e.g., Maxham and Netemeyer 2002; Smith et al., 1999), appear concerned about the service failure and make efforts towards addressing the inconvenience caused (e.g., Homburg and Fürst 2005; Karatepe 2006).

This study focuses on distributive and procedural justice. In particular, the study examines two guarantee terms - payout and ease of invocation (hereafter EoI). Payout 
entails the compensation set in the guarantee, and EoI relates to the procedures of invoking the guarantee. When guarantees function as recovery strategies, payout size is likely to influence perceptions of receiving fair (or unfair) recovery compensation, affirming distributive justice. Further, EoI is likely to influence perceptions that recovery procedures are timely, affirming procedural justice. Given that the manner in which employees interact with the customer in a recovery situation is not contingent upon the terms set in the guarantee, the dimension of interactional justice is not included in the present study.

\subsection{The impact of service guarantee terms on perceived justice}

The impact of service guarantee terms on distributive and procedural justice can be explained by signaling theory (Spence, 1973). A fundamental tenet of signaling theory is that, 'different parties to a transaction often have different amounts of information regarding the transaction' in a condition known as 'information asymmetry' (Kirmani and Rao, 2000, p. 66). Conditions of information asymmetry exist in a variety of settings. For example, the seminar paper by Spence (1973) illustrates conditions of information asymmetry between employers and job applicants in the context of hiring decisions. In this context, employers often lack information about the productive capabilities of job applicants. Job applicants, therefore, use signaling in order to ease the employer's hiring decisions. In the context of customer-firm exchanges, conditions of information asymmetry are encountered for instance at the time of buying a product, wherein several products are available and differences in the quality of the offering are often unobservable. Through signals, firms convey the quality attributes of products. Signaling is also highly relevant to service contexts, given that the characteristics inherent to services are often unobservable and consumers encounter conditions of information asymmetry (Jha et al., 2013). 
In conditions of information asymmetry, the party holding a greater amount of information attempts to create positive impressions on the party lacking information by using signals. Signals represent 'activities or attributes of individuals in a market which, by design or accident, alter the beliefs of, or convey information to, other individuals in the market' (Spence, 1974, p. 1). Extant research shows that service guarantees influence customer purchase decisions by means of signaling quality and the firm's intentions in a variety of service contexts, including education (McCollough and Gremler, 1999), hotel (Chen et al., 2009; McQuilken et al., 2013; Wirtz et al., 2000; Wu et al., 2012), and restaurant (Jin and He, 2013). A summary of key studies on service guarantees is included in Appendix 1.

The relevance of signaling in shaping customer purchase decisions (pre-consumption stage) is well established, as illustrated in the summary of literature. Concurrently, consensus is growing that signaling influences customer repurchase decisions (post-consumption stage) (e.g., Dutta et al., 2007; McCollough and Gremler, 2004; San Martin and Camarero, 2005; McQuilken et al., 2013). The present study adopts the perspective that signaling is relevant post-purchase, in service failure and recovery contexts. Signals are relevant following service failures, wherein customers face conditions of information asymmetry related to the decision to repatronize the firm. At the recovery stage, service guarantees can facilitate customer repurchase decisions by signaling that the firm acts fairly.

In the role of a signal, service guarantees represent 'a persuasive message that includes both the level of compensation and the process of invoking the guarantee to receive the compensation' (Jin and He, 2013, p. 209). Signaling research classifies service guarantees as a default-contingent signal, by which the firm conveys its commitment to incur a monetary loss in the event of default on its claim (e.g., the service turns out to be of poor quality) (Kirmani and Rao, 2000). This signal fulfils two main functions, a) informing customers about the quality of the service and about the firm's intentions, and b) protecting 
the customer against losses associated with service failures (Dutta et al., 2007). Both functions are relevant to service failure and recovery contexts. When encountering a service failure, customers re-evaluate the information conveyed by the guarantee, and they infer the firm's motives for offering the policy (Dutta et al., 2007). Customers also use the protection communicated by guarantee payout and EoI as reference point in forming perceptions of justice. In the present study, guarantee payout and EoI are hypothesised to influence customer perceptions of distributive and procedural justice, as discussed below.

\subsection{Guarantee payout}

Guarantee payout involves the monetary compensation included in the service guarantee and provided to the customer following a service failure (McDougall et al., 1998). From a signaling perspective, guarantee payout indicates the firm's signaling costs, thus the asset or wealth forfeited by the firm as a result of signaling (Ippolito, 1990). Signals are credible when firms incur high costs of signaling (Kirmani and Rao, 2000), as indicated by large payout. Research on price guarantees shows that perceived credibility and fairness of these policies increase with the size of refund set as payout (Kukar-Kinney et al., 2007). The above effects are explained by the equity theory (Adams, 1965) suggesting that a social exchange is restored at equitable levels when the parties in the exchange receive benefits that outweigh their sacrifices (or investments).

Extending the above evidence to a service guarantee context, the present study posits that the size of guarantee payout provided as compensation for the service failure will impact customer perceptions of fairness. Consistent with the above logic from equity theory (Adams, 1965), guarantee payout creates distributive justice (fairness) when delivering benefits to the customer that outweigh the sacrifices incurred as a result of the service failure and of lodging a complaint. When service failures occur, customers experience and 
inconvenience and make an effort in lodging a complaint (i.e. perceived sacrifices). Guarantee payout in the form of a discount (i.e. low payout) is unlikely to overcome the sacrifices initially incurred. By contrast, a guarantee payout in the form of full refund (i.e. medium payout) is likely to offset the effort made by the customer and to restore the customer-firm relationship to an equitable level. Accordingly, it is hypothesised that:

Hla When service recovery is implemented through a service guarantee, customers who receive medium guarantee payout will show higher perceptions of distributive justice than customers who receive low guarantee payout.

On occasions companies may over-compensate customers. The literature refers to the principles of mental accounting for explaining the effect of overcompensation on consumer responses. According to the mental accounting principles (Kahneman and Tversky, 1984), consumers interpret the service failure as a 'loss' and service recovery as a 'gain'. When compared with simple compensation, overcompensation provides large gains that fully overcome the losses incurred as a result of the service failure. Overcompensation should, therefore, result in more positive outcomes than simple compensation. Yet, extant research shows contrasting findings in the above respect. Evidence provides support for the explanation from equity theory (Adams, 1965), whereby large compensation creates positive inequity and concurring feelings of guilt amongst consumers.

Smith et al. (1999) note that moderate recovery compensation shows a greater effect on distributive justice perceptions than high compensation, especially when service failures are of low severity. Further, Noone and Lee (2011) demonstrate that whilst cash-based overcompensation is preferred over voucher-based overcompensation, the effect of overcompensation on customer repatronage intentions does not surpass the effect of compensation alone. Consistent with the above evidence, Gelbrich and Roschk (2011) note 
that overcompensation following service failures leads to an increase in overall satisfaction, which is still smaller than the effect of simple compensation.

Whilst research in this area examines customer satisfaction with high recovery compensation delivered by initiative of the firm and its employees (e.g., Hocutt et al., 2006; None and Lee, 2011; Smith et al., 1999), the role of guarantee payout as a form of overcompensation and its impact on customer perceptions of justice has so far been overlooked. Kumar et al. (1997) suggest further research on service guarantees that 'investigates important issues such as the determination of the optimum levels of compensation and the impact of over- and under-compensation' (p. 313). The above viewpoint is shared by other researchers (e.g., Jin and He, 2013; McQuilken et al., 2013). Attempting to answer the above calls for research, this study examines the impact of overcompensation rendered by guarantee payout on customer perceptions of distributive justice, at the recovery stage. Consistent with the equity theory, the study posits that guarantee payout in the form of full refund (i.e. medium payout) will be perceived as just, more than a guarantee payout that overcompensates customers by including full refund plus discount (i.e. high payout). Thus, it is hypothesised that:

HIb When service recovery is implemented through a service guarantee, customers who receive high guarantee payout will show lower perceptions of distributive justice than customers who receive low or medium guarantee payout.

\section{$2.4 \quad$ Ease of invocation}

EoI entails the complexity of the process of invoking the guarantee payout. Perceived complexity of the invocation process relates to the amount of effort put by the customer in order to invoke the guarantee (Wirtz and Kum, 2004). The policy invocation process is considered to be 'easy' when no questions are asked, or 'difficult' when the customer needs 
to submit a written claim, provide a proof of purchase, wait for notification, and sometimes physically return to the firm's premises to collect the payout (Jin and He, 2013). Hart (1988) suggests that service guarantees are effective when easy-to-invoke. The author argues that a guarantee containing several conditions that make it difficult for customers to invoke 'loses its point' (p. 56). Difficult-to-invoke guarantees can exacerbate customer dissatisfaction following service failures.

Beyond the above suggestions, EoI has so far received relatively little research attention. Exceptions are the studies by Jin and He (2013) showing that easy-to-invoke guarantees have a greater positive influence on customer decisions than difficult-to-invoke guarantees, and Meyer et al. (2014) demonstrating that service guarantees increase the firm's market value when including straightforward invocation processes. Notwithstanding, research that addresses the role of EoI in signaling the firm's quality of fairness in a recovery context is currently lacking. The above scarcity of empirical research is surprising given that service guarantees are invoked when services fail, and thus function as recovery strategies. When service guarantees function as recovery strategies, EoI is likely to influence the perceived timeliness of the recovery process. Given that timeliness is a key principle of procedural justice (e.g., Chebat and Slusarczyk, 2005), EoI is expected to impact customer perceptions of procedural justice.

When service guarantees are difficult-to-invoke, the customer may need to go through a complex process of filling up forms and providing evidence of the service failure encountered. Difficult-to-invoke guarantees can, therefore, lengthen the recovery process and delay the delivery of payout. As a result, customers are expected to perceive the timeliness of recovery to be low, and thus report low procedural justice perceptions. Conversely, easy-to-invoke guarantees enable a quick collection of payout and timely 
recovery. Accordingly, easy-to-invoke guarantees are expected to foster high perceptions of procedural justice. Thus, it is hypothesised that:

$H 2 a, b$ When service recovery is implemented through a service guarantee, customers dealing with an easy or moderately easy-to-invoke guarantee will show higher perceptions of procedural justice than customers who deal with a difficult-to-invoke guarantee.

\subsection{The interaction effect of guarantee payout and ease of invocation}

Extant signaling research suggests that the effects of payout and EoI can be interdependent. For instance, Wirtz and Kum (2004) show that customers report lower intentions to cheat on the guarantee by faking dissatisfaction when this policy includes high payout and it is easy-to-invoke, rather than difficult-to-invoke. These authors attribute the finding to customer willingness to show honesty in return for the trust signaled by the firm by offering an easy-to-invoke guarantee, including high payout. Further, when the timeframe of customer purchase decisions is considered, Jin and He (2013) show that easy-to-invoke guarantees combined with high payout encourage imminent purchase decisions.

Whilst the above studies examine the interplay between payout and EoI in influencing customer cheating and purchase intentions, the simultaneous impact of the two guarantee terms on customer perceptions of recovery fairness and related repatronage intentions is undetermined. The present study postulates an interaction effect between payout and EoI in shaping customer perceptions of justice. From a signaling perspective, guarantee payout and EoI signal the firm's fairness in handling service failures and thus influence customer perceptions of justice. Customers are likely to perceive added benefits from the recovery encounter when receiving payout in the form of full refund plus discount, and the processes of invoking the guarantee are easy. Such added benefits are likely to lead to high distributive justice perceptions. Given that distributive justice perceptions are obtained when perceived 
benefits of an exchange are greater than incurred sacrifices (Adams, 1965), easy processes of invoking the guarantee combined with payout in the form of full refund plus discount are expected to enhance distributive justice perceptions. Thus, it is postulated that:

H3a When service recovery is implemented through a service guarantee, customers who receive high payout as part of an easy-to-invoke guarantee will show higher perceptions of distributive justice than customers who receive low payout as part of a difficult-to-invoke guarantee.

Further, when easy-to-invoke guarantees are combined with full refund and discount, the process of invoking the guarantee is likely to be perceived as seamless and worth the effort, due to the substantial monetary benefit. As a result, perceptions of procedural justice are expected to be enhanced accordingly. Thus, it is postulated that:

$H 3 b$ When service recovery is implemented through a service guarantee, customers who receive high payout as part of an easy-to-invoke guarantee will show higher perceptions of procedural justice than customers who receive low payout as part of a difficult-to-invoke guarantee.

\subsection{The role of negative motive inferences}

Prior research suggests that signals are typically used to convey information about the intentions and unobservable qualities of the firm (e.g., Kirmani and Rao, 2000; San Martín and Camarero, 2005). When evaluating signals, customers thus form perceptions of the firm's qualities and infer the firm's intentions. Several scholars have noted the relevance of inferences about the firm's intentions in explaining customer perceptions of fairness. In the context of price guarantees, for instance, customer inferences about the firm's intentions/motivations for offering the policy are found to influence the impact of payout set 
in the guarantee on customer perceptions of price fairness (Kukar-Kinney et al., 2007). Further, Björlin-Lidén and Edvardsson (2003) note the relevance of such inferences in the context of service guarantees. In their study, findings from focus groups reveal that consumers are suspicious of guarantees, which are perceived to meet the firm's need to create a steady flow of customers. Similarly, McQuilken et al. (2013) speculate that the level of payout, whether higher or lower to the level set in the guarantee, raises suspicion about the intentions of the firm.

The above indicates that the way guarantees are designed can trigger customer inferences about the firm's motivations for offering these policies, either positive (customeroriented) or negative (firm-oriented). Inferences of motives are theoretically grounded in the Attribution Theory (Heider, 1958; Weiner, 1986), wherein attribution is the process of establishing the causes of events, especially surprising or negative events. These causes are often not directly observable, causality thus represents an ascription imposed by the individual, which is either inferred or speculated (Weiner, 1986).

Service recovery research has so far focused on understanding customer responses to service failures through the lens of locus, stability and controllability attributions (e.g., Blodgett et al., 1993; Hess et al., 2003; Swanson and Kelley, 2001), whilst overlooking attributions of motive. An exception is Joireman et al. (2013) who examine how inferences of motives impact customer anger and related desires for revenge and/or reconciliation. Joireman et al. (2013) examine inferences of the firm's motives following 'double deviation' scenarios, wherein both the initial service and the recovery fail. However, in the above study, inferred motive is not examined in relation to one-off service failures. Additionally, Joireman et al. (2013) do not consider customer perceptions of justice.

This study examines how differential levels of service guarantee terms impact customer inferences of the firm's motives, and how such inferences influence perceptions of 
justice in one-off service failure and recovery encounters. The hypothesised impact of guarantee terms on customer inferences of motives finds theoretical explanation in the signaling theory (Spence, 1973, 1974). Consistent with signaling theory, the size of guarantee payout indicates the firm's commitment to incur a cost as a result of a service failure (e.g., Hart et al., 1992; McDougall et al., 1998; San Martín and Camarero, 2005). In this regard, greater the size of guarantee payout, higher is the signaled commitment of the firm towards the cost of compensating the customer fairly. Customers are expected to be less likely to attribute guarantee payout in the form of full refund or refund plus discount to the firm's negative motives of increasing profits. Conversely, payout in the form of a discount signals the firm's commitment of incurring a low cost following the service failure, and it shows that the firm's commitment to fairness is low as well. Customers are, therefore, likely to infer negative firm motives (i.e. to increase profits) for offering guarantee payout in the form of a discount. Thus, it is hypothesised that:

$H 4 a, b$ When service recovery is implemented through a service guarantee, customers who receive high or medium guarantee payout will show lower inferences of firm's negative motives than customers who receive low guarantee payout.

Signaling research also suggests that guarantees are meaningful when easy-to-invoke (Hart, 1988). By setting easy procedures of invocation, the firm signals its commitment towards delivering timely recovery and its trust that customers will avoid opportunistic claiming of the guarantee (Wirtz and Kum, 2004). Conversely, difficult-to-invoke guarantees signal the firm's attempt to discourage customers from claiming this policy (Wirtz and Kum, 2004). Hence, when a guarantee policy is difficult-to-invoke, customers are expected to infer the firm's negative motive of increasing profits. Thus, it is hypothesised that: 
$H 5 a, b$ When service recovery is implemented through a service guarantee, customers dealing with an easy or moderately easy-to-invoke guarantee will show lower inferences of firm's negative motives than customers who deal with a difficult-to-invoke guarantee.

Furthermore, inferences of the firm's motive for offering the guarantee are expected to influence customer perceptions of recovery fairness. Examining perceptions towards price fairness, Campbell (1999) demonstrates that perceived price fairness lowers as customers attribute price increases to negative motives of the firm. The present study posits that inferences of negative motive will diminish perceptions of distributive justice towards the guarantee. When negative motives are inferred, customers are expected to question the firm's commitment towards delivering distributive justice and towards protecting customers against future losses in the event service failures re-occur. Thus, it is hypothesised that:

H6a When service recovery is implemented through a service guarantee, customer inferences of firm's negative motives will have a negative influence on perceptions of distributive justice.

Additionally, inferences of negative motives are expected to diminish perceptions of procedural justice. When the firm is believed to offer the guarantee in order to meet its own interests of increasing profits, customers are expected to question the firm's commitment towards rendering procedural justice and towards providing timely recovery in the event service failures re-occur. Hence, it is hypothesised that:

$H 6 b$ When service recovery is implemented through a service guarantee, customer inferences of firm's negative motives will have a negative influence on perceptions of procedural justice. 
The impact of perceived justice on customer repatronage intentions is well documented in the extant service recovery literature (e.g., Blodgett et al., 1993; Choi and Choi, 2014; Homburg and Fürst, 2005). Overall, the studies explain the above impact as the result of, a) a direct relationship (e.g., Blodgett et al., 1993), or b) an indirect relationship through the mediation of customer satisfaction (e.g., Maxham and Netemeyer, 2002). However, prior studies have examined perceived justice following employee-initiated recovery efforts, rather than perceived justice related to service recovery implemented through service guarantees. The present study hypothesises a direct relationship between perceived justice (both distributive and procedural) rendered by the service guarantee, and repatronage intentions.

The above hypothesis is theoretically explained by the reciprocity norm (Gouldner, 1960), suggesting that individuals are inclined to help those who have helped them. In this regard, studies have shown that perceived fairness generates feelings of reciprocity (e.g., Grégoire et al., 2009; Van Vaerenbergh et al., 2012). For instance, Grégoire et al. (2009) note that customers holding a good relationship with the firm reciprocate fair recovery by showing lower intentions to take revenge. In a similar way, the present study postulates that customers will reciprocate distributive and procedural fairness rendered through the guarantee by showing repatronage intentions. Hence:

$H 7 a$ When service recovery is implemented through a service guarantee, customer perceptions of distributive justice will have a positive influence on repatronage intentions.

$H 7 b$ When service recovery is implemented through a service guarantee, customer perceptions of procedural justice will have a positive influence on repatronage intentions. 


\section{Methodology}

\subsection{Design and participants}

In order to address the study's objectives, a scenario-based experimental approach was employed. This approach has been widely used in service research (e.g., Chebat and Slusarczyk, 2005; Zhu et al., 2013). Scenario-based experiments are a cost-effective method for measuring customer perceptions towards naturally occurring events such as service failure and recovery. Further, scenario-based experiments overcome issues of recall bias associated with self-reporting techniques, and assist with the control of manipulations (Smith et al., 1999).

The experiment followed a $3 \times 3$ between-subjects factorial design, leading to nine experimental conditions. The experiment included two factors, which were manipulated at three levels: guarantee payout (high/medium/low) and EoI (high/medium/low). The 'medium' condition designated the promise signaled by the guarantee, whereas 'high' and 'low' conditions referred to more, or less, than what was signaled by the guarantee. Payout was operationalised by manipulating the generosity of compensation provided at the recovery stage, following the invocation of the guarantee: full refund plus $25 \%$ discount (high payout), full refund (medium payout), and 10\% discount (low payout). EoI was operationalised by manipulating the complexity of the policy invocation process: filling in an online claim form (high EoI), filling in a claim form and emailing it to the Customer Relations Team (medium EoI), and filling in a claim form detailing what went wrong, along with a proof of purchase, mailing it to the Customer Relations Team and waiting for a validity check of the claim (low EoI). A summary of the experimental conditions is provided in Appendix 2. 
The scenarios were designed in two stages: 1) secondary research was conducted in order to identify the features of service guarantees offered in the marketplace, and 2) relevant features were incorporated in the scenarios and two pre-tests were conducted. Parcel delivery service was selected as service context for three main reasons. First, the demand for parcel delivery services is currently increasing due to the growth of online retailing, and in the UK the sector is expected to grow rapidly and reach a projected value of $£ 19$ bn by 2017 (KeyNote, 2013). Consumers are familiar with this type of service and they can easily imagine themselves in the scenarios created for the study. Second, this sector frequently experiences service failures (e.g., delays in parcel deliveries during festive seasons, KeyNote, 2013). Results from the pre-tests confirmed that most respondents encountered failures with delivery services in the past. Third, secondary research revealed that parcel delivery companies frequently employ service guarantee policies.

Consistent with a between-subjects design, respondents were randomly assigned to one of the nine experimental conditions. Respondents included a sample of UK consumers selected by means of snowball sampling technique. The average sample size for the nine experimental conditions was 15 respondents. Altogether 139 valid responses were obtained, giving a response rate of 62 per cent. The sample included 57 per cent females, 43 per cent males, 64 per cent below 34 years, 21 per cent in the 35-44 age group, and 15 per cent over 45 years. The majority of respondents reported using parcel delivery service three or more times a year (63 per cent), followed by those who used this service twice (12 per cent) or once a year (25 per cent).

\subsection{Procedure}

The data were collected using a self-completion questionnaire embedding scenarios of service failure and recovery. The questionnaire was designed and administered online, via 
the electronic survey building software Qualtrics. Respondents were sent a URL link directing them to the questionnaire. At the beginning of the questionnaire, the respondents were asked general questions about their residence, their usage and past experience using parcel delivery services. Next, the respondents were asked to imagine that they had purchased a guaranteed next day parcel delivery service from a fictitious company called ABC Express. The guaranteed next day delivery service was advertised on the company's website, where they made the purchase (see Appendix 3). The respondents were asked to imagine that they had experienced a late parcel delivery (service failure) and lodged a complaint. In the recovery encounter, respondents imagined they had invoked the guarantee. After reading the recovery scenario, respondents answered a battery of closed-ended questions regarding their perceptions of justice, inferences of motive, and repatronage intentions. The realism of service failure and recovery scenarios and the validity of the experimental manipulations were checked, as recommended by Perdue and Summers (1986).

\subsection{Measures}

Established multi-item scales were adopted and contextualised for the study. Eight items from Maxham and Netemeyer (2002) to measure distributive justice and procedural justice, three items from Kukar-Kinney et al. (2007) to measure inferred motive, and two items from Schoefer and Diamantopoulos (2008) to measure repatronage intentions, all on a 7-point Likert-type scale anchored at $1=$ strongly disagree and $7=$ strongly agree, were adopted. Three realism check items from Sparks and McColl-Kennedy (2001) were borrowed. Two bipolar items from Wirtz and Kum (2004) were used as manipulation check measures for payout and EoI. Age, gender and failure severity were included as covariates, consistent with prior research (e.g., Zhu et al., 2013). The measures used in this study are presented in Table 1 below. 
Table 1 Measures

\begin{tabular}{|c|c|}
\hline Constructs & Measurement items \\
\hline $\begin{array}{l}\text { Distributive } \\
\text { Justice }\end{array}$ & $\begin{array}{l}\text { - Although the late delivery caused me problems, the effort } \\
\text { put by ABC Express resulted in a positive outcome for me. } \\
\text { - The compensation received as part of the guarantee was fair, } \\
\text { given the time and effort spent in lodging a complaint. } \\
\text { - Given the inconvenience caused by the late delivery, the } \\
\text { compensation received from ABC Express' guarantee was } \\
\text { fair. } \\
\text { - Overall, the guarantee compensation I received in response } \\
\text { to the late delivery was more than fair. }\end{array}$ \\
\hline $\begin{array}{l}\text { Procedural } \\
\text { Justice }\end{array}$ & $\begin{array}{l}\text { - Following the late delivery, the guarantee invocation } \\
\text { resulted in a quick response from ABC Express. } \\
\text { - I feel ABC Express responded in a timely fashion to the late } \\
\text { delivery. } \\
\text { - With respect to the guarantee policy advertised on its } \\
\text { website, ABC Express handled my late delivery in a fair } \\
\text { manner. } \\
\text { - Overall ABC Express has a fair guarantee policy to handle } \\
\text { late parcel deliveries. }\end{array}$ \\
\hline Inferred Motive & $\begin{array}{l}\text { - ABC Express is serving its own interests by offering the } \\
\text { advertised guarantee. } \\
\text { - ABC Express offers the advertised guarantee to increase its } \\
\text { profits at the expense of customers. } \\
\text { - ABC Express intends to take advantage of customers by } \\
\text { offering the advertised guarantee. }\end{array}$ \\
\hline $\begin{array}{l}\text { Repatronage } \\
\text { Intentions }\end{array}$ & $\begin{array}{l}\text { - I would consider using the delivery service of ABC Express } \\
\text { in the future. } \\
\text { - I will use ABC Express if I need to buy parcel delivery } \\
\text { services again. }\end{array}$ \\
\hline
\end{tabular}

Note: All items were measured on a 7-point Likert-type scale anchored at 1='strongly disagree' and $7=$ 'strongly agree'

\subsection{Realism and manipulation checks}

Two pre-tests were conducted $(n=45)$. The main objective of the pre-tests was to establish the realism of the scenarios and that the experimental manipulations worked as intended. Realism checks were conducted by asking respondents the extent to which they thought the situation depicted in the scenario could happen in real life, and whether they 
could imagine themselves as the customer. Both the service failure and the recovery scenarios were perceived as realistic, with mean ratings greater than 5 on a 7-point scale (failure $M=5.76, S D=1.25$; recovery $M=5.58, S D=1.06$ ). Thus, the ecological validity of the study was confirmed.

Manipulation checks for payout were conducted by asking respondents to indicate the generosity of guarantee payout received at the recovery stage. Respondents perceived the generosity of guarantee payout in the form of discount only to be significantly lower than refund or refund plus discount $F_{(2,138)}=36.712, p<.05$. Manipulation checks for EoI were conducted by asking respondents to indicate the complexity of the policy invocation process. Respondents perceived the invocation process to be significantly more complex when asked to complete a claim form, mail it to the Customer Relations Team and wait for a validity check of the claim, as compared to when asked to fill in a claim form and mail it to the Customer Relations Team, or fill in an online form $F_{(2,138)}=4.999, p<.05$. In sum, the manipulation check results supported the effectiveness of the manipulations of payout and EoI.

\subsection{Analysis and results}

In order to test the research hypotheses, Partial Least Squares Structural Equation Modeling (PLS-SEM) analysis was conducted using SmartPLS 3.0 software (Ringle et al., 2014). Unlike MANOVA, structural equation analysis of experimental data allows for a complete modeling of theoretical relations, and for testing of the measurement and structural models simultaneously, thereby accounting for measurement error (Bagozzi and Yi, 1989). In addition, the PLS approach to structural equation analysis is preferred over covariancebased approaches when assumptions of multivariate normality are violated and the sample size is small (e.g., Bagozzi et al., 1991; Chin, 2010; Hair et al., 2014). A dummy variable 
approach was followed, as recommended by Bagozzi and Yi (1989). Dummy variables were created for the experimental manipulations of payout and EoI (coded as 0,1, with the 'low' manipulation representing the reference level). The dummy variables functioned as singleitem constructs and the paths from the dummy variables to the latent (multi-item) dependent variable reflected the difference in the means of the latent (multi-item) construct.

For hypotheses testing, PLS-SEM typically follows a two-step approach. First, the measurement model is assessed, and second the structural model is examined (Hair et al., 2014). Given the reflective constructs in the model, the measures were inspected for internal consistency reliability, as well as for convergent and discriminant validity. Results from the measurement model assessment are summarised in Table 2 below.

Table 2 Reliability and validity measures

\begin{tabular}{lccc}
\hline & $\begin{array}{c}\text { Cronbach's } \\
\text { Alpha }(\boldsymbol{\alpha})\end{array}$ & $\begin{array}{c}\text { Composite } \\
\text { Reliability }\left(\mathbf{P}_{\mathbf{c}}\right)\end{array}$ & $\begin{array}{c}\text { Average Variance } \\
\text { Extracted (AVE) }\end{array}$ \\
\hline Distributive Justice & 0.943 & 0.959 & 0.855 \\
Procedural Justice & 0.927 & 0.948 & 0.821 \\
Inferred Motive & 0.861 & 0.935 & 0.877 \\
Repatronage & 0.906 & 0.955 & 0.914 \\
\hline
\end{tabular}

Cronbach's alpha and composite reliability estimates were above the recommended thresholds of 0.7 , thus confirming the internal consistency reliability of the scales (Henseler et al., 2009). The loadings of the single items on the corresponding construct were well above the acceptable cut-off point of 0.7 , with the exception of one item for inferred motive (loading below 0.3). After the removal of this item (following Hair et al., 2014; Joireman et al., 2013), all items showed loadings greater than 0.7 , thus item reliability was confirmed. Further, all constructs showed Average Variance Extracted (AVE) estimates exceeding the threshold of 0.5, thus confirming convergent validity (Chin, 1998). Finally, discriminant validity was established by using Fornell and Larcker's criterion (1981); the squared 
correlations of a construct's AVE (values in boldface on the diagonal line of Table 3) were higher than their bivariate correlations with other constructs.

Table 3 Discriminant validity

\begin{tabular}{lcccc}
\hline & DJ & $\begin{array}{c}\text { Inferred } \\
\text { Motive }\end{array}$ & PJ & Repatronage \\
\hline DJ & $\mathbf{0 . 9 2 5}$ & & & \\
Inferred Motive & -0.166 & $\mathbf{0 . 9 3 7}$ & & \\
PJ & 0.822 & -0.245 & $\mathbf{0 . 9 0 6}$ & \\
Repatronage & 0.555 & -0.125 & 0.500 & $\mathbf{0 . 9 5 6}$ \\
\hline
\end{tabular}

Note: DJ=Distributive Justice; PJ= Procedural Justice

For structural model assessment, the variance explained for the constructs (R-square), the model's predictive relevance (Stone-Geisser's Q-square), effect size $\left(f^{2}\right)$, the size and significance of the paths were examined. The results from the structural model assessment are summarised in Table 4 below. The proposed model showed high predictive accuracy for distributive justice $\left(\mathrm{R}^{2}=0.45\right)$, and moderate to weak predictive accuracy for repatronage intentions $\left(\mathrm{R}^{2}=0.31\right)$ and procedural justice $\left(\mathrm{R}^{2}=0.06\right)$. All $\mathrm{Q}^{2}$ values were positive, thus indicating high predictive validity of the overall model (Hair et al., 2014).

Table 4 Structural model results and effect sizes

\begin{tabular}{lllcccc}
\hline Hyp. & Criterion & Predictors & $\mathbf{R}^{2}$ & $\begin{array}{c}\text { Path } \\
\text { coefficients }\end{array}$ & $f^{2}$ & $\mathbf{Q}^{2}$ \\
\hline H1b & Distributive Justice & High payout & 0.445 & $0.672^{* * *}$ & 0.02 & 0.370 \\
H1a & & Medium payout & & $0.659^{* * *}$ & & \\
H3a & & Payout*EoI & & 0.223 & & \\
H6a & & Inferred Motive & & 0.014 & & \\
H2a & Procedural Justice & High EoI & 0.060 & 0.003 & 0.10 & 0.038 \\
H2b & & Medium EoI & & 0.005 & & \\
H3b & & Payout*EoI & & 0.461 & & \\
H6b & & Inferred Motive & & $-0.254^{* * *}$ & & \\
H4a & Inferred Motive & High payout & 0.094 & $-0.208^{* *}$ & & 0.066 \\
H4b & & Medium payout & & $-0.348^{* * *}$ & & \\
H5a & & High EoI & & -0.008 & & \\
H5b & & Medium EoI & & 0.059 & & \\
H7a & Repatronage & Distributive Justice & 0.314 & $0.446^{* * *}$ & & 0.272 \\
H7b & & Procedural Justice & & 0.136 & & \\
\hline
\end{tabular}

Note: $* p<.10 ; * * p<.05 ; * * * p<.01 ;$ EoI=Ease of Invocation 
To estimate the structural paths, a bootstrap resampling procedure using 5,000 subsamples was followed (Hair et al., 2014). The results showed that payout in the form of full refund, as set in the guarantee, is perceived to be fair and leads to distributive justice perceptions (path coefficient $=0.672, t=9.10$ ). Guarantee payout including full refund plus discount is also perceived as being fairer than receiving $10 \%$ discount, yet not more than refund alone (path coefficient $=0.659, t=10.09$ ). Hence, H1 is supported. As hypothesised, consumers report equal perceptions of distributive justice when receiving guarantee payout in the form of full refund, or full refund plus discount. Yet, distributive justice decreases sharply when only $10 \%$ discount is received. By contrast, easy or moderately easy-to-invoke guarantees do not lead to greater perceptions of procedural justice, than difficult-to-invoke guarantees (path coefficients $=0.003-0.005, t=0.006-0.046$ ). Hence, $\mathrm{H} 2$ is not supported.

Results from the product indicator approach for testing interaction effects revealed that the payout $\mathrm{x}$ EoI path is not significantly related to distributive justice (path coefficient $=0.223, t=0.81$ ) or to procedural justice (path coefficient $=0.461, t=1.42$ ). Therefore, H3 is not supported. Interestingly, the payout $\mathrm{x}$ EoI path is significant in predicting distributive justice when the guarantee is easy-to-invoke, and it includes full refund rather than full refund plus discount (path coefficient $=0.507, t=1.92$ ). Similarly, the payout $\mathrm{x}$ EoI path is significant in predicting procedural justice when the guarantee includes full refund and it is only moderately easy-to-invoke (path coefficient=-0.525, $t=1.68$ ). Although not formally hypothesised, results from these interaction effects are relevant and reveal that the effect of payout in the form of full refund, rather than full refund plus discount, on distributive justice is contingent upon the ease of invoking the guarantee. Further, moderately easy-to-invoke guarantees are indeed perceived to be fair when combined with a very large payout in the form of full refund plus discount. The inclusion of 
the interaction terms to the model yielded a significant, small effect in explaining distributive justice $\left(f^{2}=0.02\right)$ and a significant, medium effect in explaining procedural justice $\left(f^{2}=0.10\right)$.

Further, results reveal that consumers make lower inference of negative motive when receiving guarantee payout in the form of full refund plus discount (path coefficient $=-0.208$, $t=2.14$ ) or full refund (path coefficient=-0.348, $t=3.82$ ), as compared to payout in the form of a discount $(p<.05)$. In contrast, easy or moderately easy-to-invoke guarantees do not lower inferences of negative motive when compared with difficult-to-invoke guarantees ( $p>.05)$. Therefore, H4 is supported, but H5 is not. Inferences of negative motive lower perceptions of procedural justice (path coefficient $=-0.254, t=2.64$ ), but not perceptions of distributive justice (path coefficient $=0.014, t=0.29$ ). In turn, distributive justice encourages repatronage intentions (path coefficient $=0.446, t=3.72$ ), whereas procedural justice does not (path coefficient=0.136, $t=1.04$ ). Hence, H6 and H7 are partially supported. The paths and the results are depicted in Figure 1 below. 
Figure 1: PLS Path Model Results

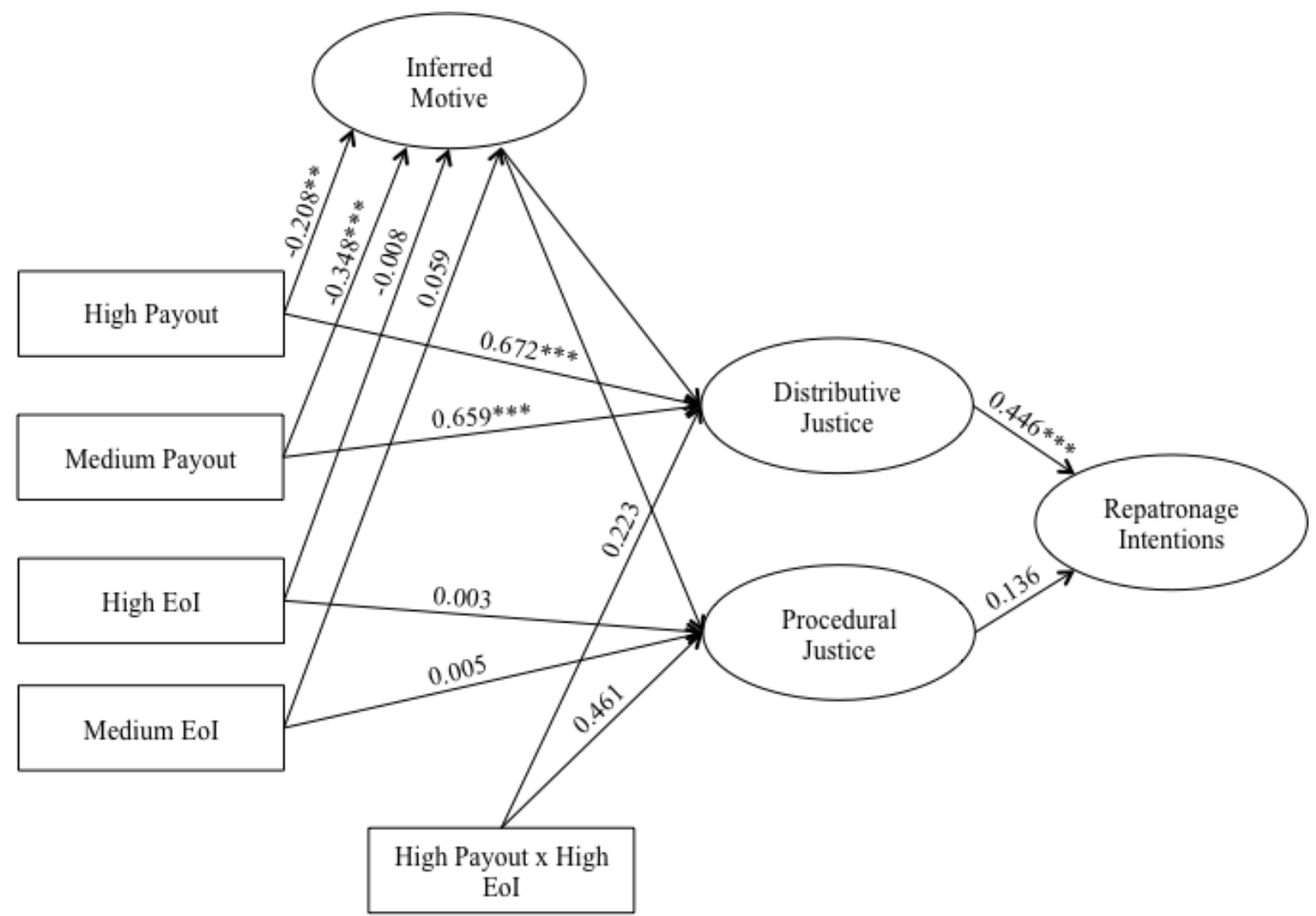

Note: Constructs on the left hand side represent dummy variables coded as 0,1 , with the 'low' condition as reference level. High Payout $=$ high vs. low; Medium Payout = medium vs. low; High EoI = high vs . low; Medium EoI = medium vs. low .

\section{Discussion and conclusions}

Understanding customer perceptions of service guarantees employed as recovery strategies represents a critical issue for service managers in order to design effective policies. When service failures occur, service guarantee policies function as recovery strategies and determine the firm's service recovery efforts. Specifically, the terms set in the guarantee influence the monetary compensation that the customers receive at the recovery stage (i.e. payout) and the processes of claiming such compensation (i.e. ease of invocation). Through the guarantee terms, the firm signals justice and its motivations for offering the policy. The present study examined the impact of two guarantee terms, namely payout and EoI, on customer perceptions of justice, inferences of the firm's motives, and consequent repatronage intentions. 
This study confirmed that perceptions of fairness towards guarantees employed as recovery strategies vary according to the level of guarantee payout. Customers show greater perceptions of distributive justice when receiving payout in the form of full refund, rather than $10 \%$ discount on the next purchase. Hence, providing a payout in the form of $10 \%$ discount is not perceived as fair recovery. The benefits associated with guarantee payout in the form of a discount do not outweigh perceived sacrifices related to the inconvenience caused by the service failure and the process of lodging a complaint. As a result, customers show low perceptions of distributive justice. On the contrary, customers perceive a double loss from the service failure and payout of $10 \%$ discount. The above finding is consistent with prior signaling literature suggesting that the perceived credibility and fairness of guarantee signals increase with the size of payout (e.g., Kukar-Kinney et al., 2007). Whilst high guarantee payout signals the firm's commitment towards incurring a large cost following service failures (Hart et al., 1992), and towards issues of fairness, payout in the form of a discount signals that the firm lacks commitment towards issues of fairness in delivering service recovery .

Remarkably, there is no extra enhancement of distributive justice perceptions when guarantee payout in the form of a full refund plus discount is provided, as compared to payout in the form of full refund. The above finding indicates that whilst overcompensation (i.e. full refund plus discount) provided through the guarantee enhances distributive justice, the above effect is not greater than the effect of compensation alone (i.e. full refund). The above finding is in line with the equity theory suggesting that overcompensation leads to positive inequity and feelings of guilt and embarassment (Adams, 1965). Customers perceive a payout which is larger than the level set in the guarantee as undeserved, and experience related feelings of guilt . 
Additionally, the above finding provides support for the contention by Gelbrich and Roschk (2011) that following service failures, customers are concerned about receiving compensation that reduces the losses incurred, more than compensation that maximises gains. The level of overcompensation set in the experimental scenarios included in the present study may also explain the finding. In particular, the specificity of the information in the medium payout condition, wherein payout is in the form of full refund, could have led respondents to perceive full refund as more salient in reducing the losses encountered, than information about overcompensation. As a result, overcompensation delivered through the guarantee does not lead enhancements in distributive justice perceptions.

By contrast, the process of invoking the guarantee, whether highly or only slightly complicated, does not lead to perceptions of procedural justice. This finding diverges from the contention by Hart (1988) that guarantees are most effective when easy-to-invoke. When a service guarantee is employed as a recovery strategy, the ease of invoking the guarantee does not lead to positive perceptions of justice. The above finding means that the ease of guarantee invocation process is not essential for effective service recovery management. An explanation for this finding is that customers are generally accustomed to lengthy processes of claiming guarantee policies. Their level of acceptance of lengthy invocation processes is high, and their perceptions of procedural justice, therefore, do not enhance when guarantees are very easy-to-invoke.

It is noteworthy that when guarantee payout and EoI are examined in combination, their interaction does not lead to significant changes in customer perceptions of distributive and procedural justice. This result, at first, suggests that guarantee payout and EoI have an independent effect on perceived justice. Yet, an inspection of the interaction between payout as full refund and moderately easy processes of invoking the guarantee offers interesting insights. The interaction effects between full refund and easy invocation processes, and 
between full refund plus discount and moderately easy invocation processes, are indeed significant. The above findings suggest that the effect of full refund, as set in the guarantee, in enhancing perceptions of distributive justice is contingent upon the ease of invoking the guarantee. Similarly, the effect of moderately easy-to-invoke guarantees in enhancing perceptions of procedural justice is contingent upon the provision of substantial payout, including full refund plus discount.

The above reported lack of interaction effect between payout in the form of full refund plus discount and easy invocation processes does not support the findings by Wirtz and Kum (2004) who show that, in reference to customer cheating intentions, guarantees that include substantial payout and easy invocation processes work best at preventing customer cheating behaviour. This divergence of findings could be attributed to the context in which the guarantee is invoked following a service failure. When experiencing a service failure, customers perceive guarantee payout to be fair if the process of invoking the guarantee is easy and it leads to timely resolution of the problem, though no additional redress for the inconvenience is offered. By contrast, recovery processes are perceived to be fair if the guarantee invocation process is complicated, but it results in substantial monetary benefit.

Another important finding of this study is that the inferences of negative motive vary according to the levels of guarantee payout. This finding follows the signaling perspective suggesting that the size of guarantee payout signals the firm's commitment to incur costs due to the service failure (e.g., San Martín and Camarero, 2005). The study's findings reveal that customers report greater inferences of firm negative motives when receiving a $10 \%$ discount as guarantee payout, as compared to full refund or refund plus discount. The provision of $10 \%$ discount thus signals low firm commitment to delivering fairness and is attributed to the firm's motive to pursue its own interests of profits. Conversely, the provision of full refund or full refund plus discount signals the firm's commitment towards delivering fairness. Such 
guarantee payout is associated with the firm's motives to serve customer interests (i.e. to prevent customer losses).

In support of the contention that inferences of motive influence perceptions of justice, the study's findings show that inferences of negative motives lower perceptions of procedural justice. The above finding is consistent with the evidence on price fairness (Campbell, 1999) and price guarantees (Kukar-Kinney et al., 2007) showing that customer perceptions of price fairness diminish when price increases are attributed to the firm's self-serving motives. Similarly, in situations where service recovery is implemented through service guarantees, customers' perceptions of procedural justice diminish when the firm is believed to be serving its interests of increasing profits through the offering of a service guarantee.

Inferences of motive, however, do not diminish distributive justice perceptions. In spite of inferences that the firm uses the guarantee in order to meet its own interests of profits, customers perceive the benefits resulting from the recovery encounter to outweigh the sacrifices undergone as a result of experiencing a service failure and of lodging a complaint. Accordingly, distributive justice perceptions remain unchanged, yet foster repatronage intentions. Consistent with prior research (e.g., Grégoire et al., 2009), fairness rendered through guarantee payout generates feelings of reciprocity leading customers to show intentions to re-visit the firm. By contrast, and as expected, procedural justice lowered by inferences of negative motives does not lead to repatronage intentions.

\section{Implications for theory and practice, limitations and further research}

The present study offers a novel frame for investigating how service guarantees function in a recovery context. Specifically, the study focuses on understanding how service guarantee terms signal the firm's justice in handling service failures and the underlying 
motivations for offering these policies, thus in turn shaping customer perceptions of justice and inferences of motive. In doing so, the study makes several important theoretical contributions to service recovery research. Firstly, this study, for the first time, demonstrates that service guarantee policies play an important role as recovery strategies, given that such policies influence customer perceptions of recovery fairness.

Secondly, when service guarantees are used in a recovery context, the terms of payout and EoI not only signal the firm's fairness in handling service failures, but also the firm's underlying motivations for employing this policy. This study is the first to investigate causal attributions related to service guarantees, when the policies are implemented as recovery strategies. The findings demonstrate that inferences of motive hold theoretical relevance in explaining how customers evaluate service recovery implemented through service guarantees and how they form related perceptions of justice. Thirdly, this study demonstrates the applications of the justice, signaling and attribution theories into the domain of service recovery research. As evidenced in this study, customers' psychological processes of evaluating service recovery encounters are complex. The interface of multiple theories thus provides a useful framework in unravelling such complexities.

Further, the study's findings have notable implications for service management, especially with regards to the design of service guarantee policies. Considering the effect of guarantee payout on perceived justice and inferences of negative motives, service managers are advised to pay particular attention towards setting guarantee payout levels. The results in this study demonstrate that overcompensating the customer by offering a payout higher than the guarantee (i.e. full refund plus discount) is not a profitable strategy, given that overcompensation offered through the guarantee does not lead to enhanced justice perceptions, unless combined with moderately easy invocation processes. Delivering on the promise set by the guarantee can, however, benefit businesses more than overcompensation. 
Conversely, the provision of guarantee payout in the form of a discount can be detrimental for businesses, as customers perceive this practice to be the firm's attempt to increase profits at their expense. It follows that the design of service guarantee policies should be based on a priori assessment of, a) the likely impact of guarantee terms on customer inferences of motive, and b) the extent to which the firm can meet the financial commitment set in the guarantee, if the service fails. Finally, the complexity of the policy invocation process is contingent upon the payout set in the guarantee. Hence, service managers are recommended to align the policy invocation procedures with the size of payout.

This study has some limitations that also provide avenues for further research. First, the study could be replicated across other service contexts where service guarantees are frequently used. Whilst the hospitality sector has received attention in extant research, the same does not apply to services with 'credence' attributes (e.g., legal or medical services). Signaling effects are particularly relevant to credence services. As suggested by Walsh and Beatty (2007), credence attributes of services are notably difficult to discern before and even after consumption, thus consumers rely more on marketing signals when dealing with these services.

Second, future research could investigate additional elements of service guarantees and their effects on customer perceptions of justice and inferences of motive. For example, guarantee scope, whether unconditional or attribute-specific, can provide further insights on customer perceptions towards service guarantees, in a recovery context (e.g., Jin and He, 2013; Wirtz and Kum, 2001). An interaction effect between guarantee scope, payout and EoI is likely to emerge. Third, further research is recommended for examining contextual factors, such as firm reputation, that could moderate the effects of guarantee terms on perceived justice and inferences of motive, in a recovery context. For instance, Björlin-Lidén and 
Edvardsson (2003) argue that firm reputation influences the perceived credibility of unconditional and conditional guarantees.

Fourth, future studies could consider other outcomes of motive inferences and perceived justice, such as the relational constructs of trust and commitment. Marketing signals are found to influence customer trust in the firm by means of lowering perceived risk associated with the purchase decision (San Martín and Camarero, 2005). Whether the above effects hold when customer repurchase decisions are considered following service failures warrants empirical investigation. Fifth, this study takes a cross-sectional approach towards understanding how service guarantees signal justice in a recovery context. By employing a longitudinal design, future research could examine signaling effects over time, thereby shedding light on how perceptions of justice change as customers become knowledgeable about the payout and EoI set in service guarantee policies. 


\section{References}

Adams, J.S. (1965), "Inequity in social exchange", in Berkowitz, L. (Ed.), Advances in Experimental Psychology, Vol. 2, Academic Press, New York, NY, pp. 267-299.

Bagozzi, R.P. and Yi, Y. (1989), "On the use of structural equation models in experimental designs", Journal of Marketing Research, Vol. 26 No. 3, pp. 271-284.

Bagozzi, P.B., Yi, Y. and Singh, S. (1991), "On the use of structural equation models in experimental designs: Two extensions", International Journal of Research in Marketing, Vol. 8 No. 2, pp. 125-140.

Berman, B. and Mathur, A. (2014), "Planning and implementing effective service guarantee programs", Business Horizons, Vol. 57 No. 1, pp. 107-116.

Bies, R.J. and Moag, J.S. (1986), "Interactional justice: Communication criteria of fairness", In Lewicki, R.J., Sheppard, B.H. and Bazerman M.H. (Eds.), Research on negotiation in organizations, Vol. 1, JAI Press, Greenwich, CT, pp. 43-55.

Björlin-Lidén, S. and Edvardsson, B. (2003), "Customer expectations on service guarantees", Managing Service Quality, Vol. 13 No. 5, pp. 338-348.

Björlin-Lidén, S. and Skålén, P. (2003), "The effect of service guarantees on service recovery”, International Journal of Service Industry Management, Vol. 14 No. 1, pp. 3658.

Blau, P.M. (1964), Exchange and power in social life, Wiley, New York.

Blodgett, J.G., Granbois, D.H. and Walters, R.G. (1993), "The effects of perceived justice on complainants' negative word-of-mouth behaviour and repatronage intentions", Journal of Retailing, Vol. 69 No. 4, pp. 399-428.

Blodgett, J.G., Hill, D.J. and Tax, S.S. (1997), "The effects of distributive, procedural, and interactional justice on postcomplaint behaviour", Journal of Retailing, Vol. 73 No. 2, pp. 185-210.

Callan, R.J. and Moore, J. (1998), "Service guarantee: A strategy for service recovery", Journal of Hospitality \& Tourism Research, Vol. 22 No. 1, pp. 56-71.

Campbell, M.C. (1999), "Perceptions of price unfairness: antecedents and consequences", Journal of Marketing Research, Vol. 36 No. 2, pp. 187-199.

Chebat, J.C. and Slusarczyk, W. (2005), "How emotions mediate the effects of perceived justice on loyalty in service recovery situations: an empirical study", Journal of Business Research, Vol. 58 No. 5, pp. 664-673.

Chen, X.J., John, G., Hays, J.M., Hill, A.V. and Geurs, S.E. (2009), "Learning from a service guarantee quasi experiment", Journal of Marketing Research, Vol. 46 No. 5, pp. 584-596.

Chin, W.W. (1998), "The Partial Least Squares Approach to Structural Equation Modeling”, In Marcoulides, G.A. (Ed.), Modern Methods of Business Research, Lawrence Erlbaum Associates, London, pp. 295-333.

Chin, W.W. (2010), "How to Write Up and report PLS Analyses," in Vinzi, V.E., Chin, W.W., Henseler, J. and Wang, H. (eds.), Handbook of Partial Least Squares, SpringerVerlag, Berlin, pp. 655-690.

Choi, B. and Choi, B.J. (2014), "The effects of perceived service recovery justice on customer affection, loyalty, and word-of-mouth", European Journal of Marketing, Vol. 48 No. $1 / 2$, pp. 108-131.

del Río-Lanza, A.B., Vázquez-Casielles, R. and Díaz-Martín, A.M. (2009), "Satisfaction with service recovery: Perceived justice and emotional responses", Journal of Business Research, Vol. 62 No. 8, pp. 775-781.

Dutta, S., Biswas, A. and Grewal, D. (2007), "Low price signal default: an empirical investigation of its consequences", Journal of the Academy of Marketing Science, Vol. 35 No. 1, pp. 76-88. 
Furby, L. (1986), "Psychology and justice", in Cohen, R.L. (Ed.), Justice: Views from the Social Sciences, Plenum Press, New York, NY, pp. 153-194.

Gelbrich, K. and Roschk, H. (2011), "Do complainants appreciate overcompensation? A meta-analysis on the effect of simple compensation vs. overcompensation on postcomplaint satisfaction", Marketing Letters, Vol. 22 No. 1, pp. 31-47.

Gouldner, A.W. (1960), "The norm of reciprocity: A preliminary statement", American Sociological Review, Vol. 25 No. 2, pp. 161-178.

Grégoire, Y., Tripp, T.M. and Legoux, R. (2009), "When customer love turns into lasting hate: The effects of relationship strength and time on customer revenge and avoidance", Journal of Marketing, Vol. 73 No. 6, pp. 18-32.

Hair, J.F., Hult, G.T.M., Ringle, C.M. and Sarstedt, M. (2014), A Primer On Partial Least Squares Structural Equation Modeling (PLS-SEM), SAGE Publications, Thousand Oaks, CA.

Hart, C.W.L. (1988), “The power of unconditional service guarantees”, Harvard Business Review, July-August, pp. 54-62.

Hart, C.W.L., Schlesinger, L.A. and Maher, D. (1992), "Guarantees come to professional service firms", Sloan Management Review, Vol. 33 No. 3, pp. 19-29.

Heider, F. (1958), The Psychology of Interpersonal Relations, Wiley, New York.

Henseler, J., Ringle, C.M. and Sinkovics, R.R. (2009), "The use of partial least squares path modeling in international marketing", in Sinkovics, R.R. and Ghauri, P.N. (ed.), New Challenges to International Marketing. Advances in International Marketing, Vol. 20, Emerald Group Publishing Limited, pp. 277-319.

Hess Jr., R.L., Ganesan, S. and Klein, N.M. (2003), "Service failure and recovery: The impact of relationship factors on customer satisfaction", Journal of the Academy of Marketing Science, Vol. 31 No. 2, pp. 127-145.

Hocutt, M.A., Bowers, M.R. and Donavan, D.T. (2006), "The art of service recovery: fact or fiction?", Journal of Services Marketing, Vol. 20 No. 3, pp. 199-207.

Hogreve, J. and Gremler, D.D. (2009), "Twenty years of service guarantee research: A synthesis", Journal of Service Research, Vol. 11 No. 4, pp. 322-343.

Homans, G.C. (1961), Social behaviour. Its elementary forms, Routledge \& Kegan Paul, London.

Homburg, C. and Fürst, A. (2005), "How organizational complaint handling drives customer loyalty: An analysis of the mechanistic and the organic approach", Journal of Marketing, Vol. 69 No. 3, pp. 95-114.

Ippolito, P.M. (1990), "Bonding and Nonbonding Signals of Product Quality”, Journal of Business, Vol. 63 No. 1, pp. 41-60.

Jha, S., Deitz, G.D., Babakus, E. and Yavas, U. (2013), "The role of corporate image for quality in the formation of attitudinal service loyalty", Journal of Service Research, Vol. 16 No. 2, pp. 155-170.

Jin, L. and He, Y. (2013), "Designing service guarantees with construal fit: Effects of temporal distance on consumer responses to service guarantees", Journal of Service Research, Vol. 16 No. 2, pp. 202-215.

Joireman, J., Grégoire, Y., Devezer, B. and Tripp, T.M. (2013), "When do customers offer firms a "second chance" following a double deviation? The impact of inferred firm motives on customer revenge and reconciliation", Journal of Retailing, Vol. 89 No. 3, pp. 315-337.

Kahneman, D. and Tversky, A. (1984), "Choices, values, and frames", American Psychologist, Vol. 39 No. 4, pp. 341-350. 
Kandampully, J. and Butler, L. (2001), "Service guarantees: a strategic mechanism to minimise customers' perceived risk in service organisations", Managing Service Quality, Vol. 11 No. 2, pp. 112-121.

Karatepe, O.M. (2006), "Customer complaints and organizational responses: the effects of complainants' perceptions of justice on satisfaction and loyalty", International Journal of Hospitality Management, Vol. 25 No. 1, pp. 69-90.

KeyNote (2013), "Courier and Express Services", available at: http://www.keynote.co.uk (accessed 5 June 2014)

Kirmani, A. and Rao, A.R. (2000), "No pain, no gain: A critical review of the literature on signaling unobservable product quality", Journal of Marketing, Vol. 64 No. 2, pp. 66-79.

Kukar-Kinney, M., Xia, L. and Monroe, K.B. (2007), "Consumers' perceptions of the fairness of price-matching refund policies", Journal of Retailing, Vol. 83 No. 3, pp. 325337.

Kumar, P., Kalwani, M.U. and Dada, M. (1997), "The impact of waiting time guarantees on customers' waiting experiences”, Marketing Science, Vol. 16 No. 4, pp. 295-314.

Maxham III, J.G. and Netemeyer, R.G. (2002), "Modeling customer perceptions of complaint handling over time: the effects of perceived justice on satisfaction and intent", Journal of Retailing, Vol. 78 No. 4, pp. 239-252.

McCollough, M.A. and Gremler, D.D. (1999), "Guaranteeing student satisfaction: An exercise in treating students as customers", Journal of Marketing Education, Vol. 21 No. 2, pp. 118-130.

McCollough, M.A. and Gremler, D.D. (2004), "A conceptual model and empirical examination of the effect of service guarantees on post-purchase consumption evaluations", Managing Service Quality, Vol. 14 No. 1, pp. 58-74.

McDougall, G.H.G., Levesque, T. and VanderPlaat, P. (1998), "Designing the service guarantee: unconditional or specific?”, Journal of Services Marketing, Vol. 12 No. 4, pp. 278-293.

McQuilken, L., McDonald, H. and Vocino, A. (2013), "Is guarantee compensation enough? The important role of fix and employee effort in restoring justice", International Journal of Hospitality Management, Vol. 33 No. 1, pp. 41-50.

Meyer, J., Gremler, D.D. and Hogreve, J. (2014), "Do service guarantees guarantee greater market value?", Journal of Service Research, Vol. 17 No. 2, pp. 150-163.

Noone, B.M. and Lee, C.H. (2011), "Hotel overbooking: The effect of overcompensation on customers' reactions to denied service", Journal of Hospitality \& Tourism Research, Vol. 35 No. 3, pp. 334-357.

Ostrom, A.L. and Iacobucci, D. (1998), “The effect of guarantees on consumers' evaluations of services", Journal of Services Marketing, Vol. 12 No. 5, pp. 362-378.

Perdue, B.C. and Summers, J.O. (1986), "Checking the success of manipulations in marketing experiments", Journal of Marketing Research, Vol. 23 No. 4, pp. 317-326.

Ringle, C.M., Wende, S. and Becker, J.M. (2014), SmartPLS 3, SmartPLS, Hamburg. Retrieved from http://www.smartpls.com

Roschk, H. and Kaiser, S. (2013), "The nature of an apology: An experimental study on how to apologize after a service failure", Marketing Letters, Vol. 24 No. 3, pp. 293-309.

San Martín, S. and Camarero, C. (2005), "Consumer reactions to firm signals in asymmetric relationships”, Journal of Service Research, Vol. 8 No. 1, pp. 79-97.

Schoefer, K. and Diamantopoulos, A. (2008), "The role of emotions in translating perceptions of (In)justice into postcomplaint behavioral responses", Journal of Service Research, Vol. 11 No. 1, pp. 91-103. 
Smith, A.K., Bolton, R.N. and Wagner, J. (1999), "A model of customer satisfaction with service encounters involving failure and recovery", Journal of Marketing Research, Vol. 36 No. 3, pp. 356-372.

Sparks, B.A. and McColl-Kennedy, J.R. (2001), "Justice strategy options for increased customer satisfaction in a services recovery setting", Journal of Business Research, Vol. 54 No. 3, pp. 209-218.

Spence, A.M. (1973), "Job market signaling”, The Quarterly Journal of Economics, Vol. 87 No. 3, pp. 355-374.

Spence, A.M. (1974), Market signaling: Informational transfer in hiring and related screening processes, Harvard University Press, Cambridge Massachusetts.

Spence, A.M. (2002), "Signaling in retrospect and the informational structure of markets", American Economic Review, Vol. 92 No. 3, pp. 434-459.

Swanson, S.R. and Kelley, S.W. (2001), "Service recovery attributions and word-of-mouth intentions", European Journal of Marketing, Vol. 35 No. 1/2, pp. 194-211.

Tax, S.S., Brown, S.W. and Chandrashekaran, M. (1998), "Customer evaluations of service complaint experiences: Implications for relationship marketing”, Journal of Marketing, Vol. 62 No. 2, pp. 60-76.

Thibaut, J. and Walker, L. (1975), Procedural justice: A psychological analysis, Lawrence Erlbaum Associates, Hillsdale, NJ.

Van Vaerenberg, Y., De Keyser, A. and Larivière, B. (2014), "Customer intentions to invoke service guarantees. Do excellence in service recovery, type of guarantee and cultural orientation matter?, Managing Service Quality, Vol. 24 No. 1, pp. 45-62.

Van Vaerenbergh, Y., Larivière, B. and Vermeir, I. (2012), "The impact of process recovery communication on customer satisfaction, repurchase intentions, and word-of-mouth intentions", Journal of Service Research, Vol. 15 No. 3, pp. 262-279.

Walsh, G. and Beatty, S.E. (2007), "Customer-based corporate reputation of a service firm: scale development and validation", Journal of the Academy of Marketing Science, Vol. 35 No. 1, pp. 127-143.

Weiner, B. (1986), An attributional theory of motivation and emotion, Springer-Verlag, New York.

Wirtz, J. and Kum, D. (2001), "Designing service guarantees - is full satisfaction the best you can guarantee?”, Journal of Services Marketing, Vol. 15 No. 4, pp. 282-299.

Wirtz, J. and Kum, D. (2004), "Consumer cheating on service guarantees", Journal of the Academy of Marketing Science, Vol. 32 No. 2, pp. 159-175.

Wirtz, J., Kum, D. and Lee, K.S. (2000), "Should a firm with a reputation for outstanding service quality offer a service guarantee?", Journal of Services Marketing, Vol. 14 No. 6, pp. 502-512.

Wu, C.H.J., Liao, H.C., Hung, K.P. and Ho, Y.H. (2012), "Service guarantees in the hotel industry: Their effects on consumer risk and service quality perceptions", International Journal of Hospitality Management, Vol. 31 No. 3, pp. 757-763.

Zhu, Z., Nakata, C., Sivakumar, K. and Grewal, D. (2013), "Fix it or leave it? Customer recovery from self-service technology failures", Journal of Retailing, Vol. 89 No.1, pp. $15-29$. 


\section{Appendix 1}

\begin{tabular}{|c|c|c|}
\hline Author(s) & Key Findings & Future Research \\
\hline Hart (1988) & $\begin{array}{l}\text { - A service guarantee should be; (1) unconditional, (2) easy to understand, (3) } \\
\text { financially meaningful, (4) easy to invoke and (5) quick to collect payout. }\end{array}$ & $\begin{array}{l}\text { - Test the impact of payout size, ease of invocation, ease of understanding, and } \\
\text { the number of guarantee conditions on consumers. }\end{array}$ \\
\hline Hart et al. (1992) & $\begin{array}{l}\text { - Unconditional guarantees are helpful to firms vulnerable to NWOM. } \\
\text { - Guarantees reduce perceived risk. }\end{array}$ & $\begin{array}{l}\text { - Test; (1) how guarantees function for firms relying upon referrals; (2) how } \\
\text { implicit and explicit guarantees are used concurrently. }\end{array}$ \\
\hline $\begin{array}{l}\text { Kumar et al. } \\
\text { (1997) }\end{array}$ & $\begin{array}{l}\text { - Time guarantee, if met, increases satisfaction at the end of a wait. If } \\
\text { violated, time guarantee decreases satisfaction at the end of the wait. }\end{array}$ & $\begin{array}{l}\text { - Examine; (1) the impact of guarantee payout, over and under-compensation, (2) } \\
\text { situations of multiple waiting experiences. }\end{array}$ \\
\hline $\begin{array}{l}\text { McDougall et al. } \\
(1998)\end{array}$ & $\begin{array}{l}\text { - Consumers prefer the specific guarantee to the unconditional one. } \\
\text { - Consumers mention the importance of fair settlement such as money back. }\end{array}$ & $\begin{array}{l}\text { - Test; (1) how guarantees influence repurchase intentions, in other service } \\
\text { contexts, (2) using methods that overcome issues of recall bias. }\end{array}$ \\
\hline $\begin{array}{l}\text { Ostrom and } \\
\text { Iacobucci (1998) }\end{array}$ & $\begin{array}{l}\text { - Service guarantee leads to satisfaction and perceptions of quality. } \\
\text { - External quality information moderates the effect of the guarantee. }\end{array}$ & $\begin{array}{l}\text { - Test the impact of guarantee invocation and payout on post-purchase } \\
\text { evaluations. }\end{array}$ \\
\hline Wirtz et al. (2000) & $\begin{array}{l}\text { Explicit guarantee marginally improves quality perceptions and reduces } \\
\text { perceived risk, for good quality providers more than for outstanding ones. }\end{array}$ & $\begin{array}{l}\text { - Consider post-purchase evaluations, when guarantees are invoked } \\
\text { - Measure quality and risk perceptions as multiple-item constructs }\end{array}$ \\
\hline $\begin{array}{l}\text { Kandampully and } \\
\text { Butler (2001) }\end{array}$ & $\begin{array}{l}\text { - Guarantees influence satisfaction, trust and loyalty. } \\
\text { - Prompt service recovery, through the implementation of a service guarantee, } \\
\text { should enable firms to reduce NWOM. }\end{array}$ & $\begin{array}{l}\text { - Test; (1) the proposed model and (2) how service recovery is implemented } \\
\text { through service guarantees. }\end{array}$ \\
\hline $\begin{array}{l}\text { Wirtz and Kum } \\
(2001)\end{array}$ & $\begin{array}{l}\text { - Combined guarantees lower perceived risk and expectations of service } \\
\text { failures, more than attribute-specific guarantees. }\end{array}$ & $\begin{array}{l}\text { - Test the effect of combined guarantee post-purchase, when the guarantee is } \\
\text { invoked, with the use of multi-item scales. }\end{array}$ \\
\hline $\begin{array}{l}\text { Björlin-Lidén and } \\
\text { Edvardsson } \\
(2003)\end{array}$ & $\begin{array}{l}\text { - Customers expect clarity of terms and fairness of service guarantees. } \\
\text { - Suspicion arises when guarantees are introduced to acquire new customers. }\end{array}$ & $\begin{array}{l}\text { - Test; (1) perceived fairness of service guarantees, (2) customer suspicion of } \\
\text { guarantees and the impact on behavioural responses. }\end{array}$ \\
\hline $\begin{array}{l}\text { Björlin-Lidén and } \\
\text { Skalen (2003) }\end{array}$ & $\begin{array}{l}\text { - Guarantees influence employee recovery efforts. } \\
\text { - Service recovery perceived as unfair when employees follow the guarantee. }\end{array}$ & $\begin{array}{l}\text { - Examine, (1) how recovery process is implemented through service guarantee, } \\
\text { (2) perceptions of recovery when knowledgeable about the guarantee. }\end{array}$ \\
\hline $\begin{array}{l}\text { McCollough and } \\
\text { Gremler (2004) }\end{array}$ & $\begin{array}{l}\text { - Service guarantee signaling, differentiation and coproduction influence } \\
\text { post-consumption satisfaction, but guarantee evaluations do not. }\end{array}$ & $\begin{array}{l}\text { - Test if the effects hold when; (1) the service fails and the guarantee is invoked, } \\
\text { (2) in other service settings. }\end{array}$ \\
\hline $\begin{array}{l}\text { Wirtz and Kum } \\
(2004)\end{array}$ & $\begin{array}{l}\text { - Cheating on the guarantee lowers when intending to repatronize the firm, } \\
\text { when satisfied with the service, and having high morality. } \\
\text { - Potential material gain does not affect cheating behaviour. }\end{array}$ & $\begin{array}{l}\text { - Examine; (1) cultural differences in opportunistic behaviour, (2) whether } \\
\text { inferences of the firm's motive influence opportunistic behaviour. }\end{array}$ \\
\hline $\begin{array}{l}\text { Hogreve and } \\
\text { Gremler (2009) }\end{array}$ & $\begin{array}{l}\text { - Review of research on guarantees from } 1985 \text { to } 2008 \text { highlights increasing } \\
\text { interest in the impact of service guarantees on consumer behavior. }\end{array}$ & $\begin{array}{l}\text { - Test the impact of service guarantees on service performance, service recovery, } \\
\text { and return on service guarantee investments. }\end{array}$ \\
\hline $\begin{array}{l}\text { McQuilken and } \\
\text { Robertson (2011) }\end{array}$ & $\begin{array}{l}\text { - Guarantees encourage complaining behaviour. } \\
\text { - Failure severity interacts with active request from employee and guarantee } \\
\text { type in influencing exit behaviour. }\end{array}$ & - Examine the role of guarantee in a service recovery context. \\
\hline
\end{tabular}




\begin{tabular}{|c|c|c|}
\hline Wu et al. (2012) & $\begin{array}{l}\text { - Money-back guarantees increase perceptions of quality and lower perceived } \\
\text { risk more than non-money-back guarantees. } \\
\text { - Unconditional guarantee are most effective for reputed hotels. }\end{array}$ & - Test whether the effects hold at the post-consumption stage. \\
\hline Jin and $\mathrm{He}(2013)$ & $\begin{array}{l}\text { - Wording in the guarantee and timeframe of purchase decisions influence the } \\
\text { effect of service guarantees on perceived quality and purchase intentions. }\end{array}$ & $\begin{array}{l}\text { - Investigate; (1) other forms of compensation, (2) whether the effects hold at the } \\
\text { post-consumption stage. }\end{array}$ \\
\hline $\begin{array}{l}\text { McQuilken et al. } \\
(2013)\end{array}$ & $\begin{array}{l}\text { - Recovery compensation, fix and failure severity jointly influence } \\
\text { customers' perceptions of distributive justice when guarantee is offered. }\end{array}$ & $\begin{array}{l}\text { - Consider procedural justice when guarantee is invoked. } \\
\text { - Examine how the size of compensation influences customer suspicion. }\end{array}$ \\
\hline $\begin{array}{l}\text { Berman and } \\
\text { Mathur (2014) }\end{array}$ & $\begin{array}{l}\text { - Service guarantees benefit firms by, signaling quality, setting performance } \\
\text { standards, providing data on service failures and by regaining customers. }\end{array}$ & - Test service guarantees in the context of risky services. \\
\hline $\begin{array}{l}\text { Van Vaerenberg } \\
\text { et al. (2014) }\end{array}$ & $\begin{array}{l}\text { - Customers are likely to invoke the guarantee after unsuccessful recovery. } \\
\text { - Collectivist societies invoke the guarantee even after successful recovery. }\end{array}$ & - Consider when the guarantee is implemented as service recovery. \\
\hline
\end{tabular}




\section{Appendix 2}

\section{Scenario}

You forgot your mum's birthday. When you remember, you decide to send her a parcel containing a gift for her. You need to get the parcel delivered to your parents' house. You search online for a provider of parcel delivery services, which can deliver your parcel

Introduction quickly. While searching online, you come across a company called ABC Express. On its website, ABC Express is promoting a Premium Next Day Delivery service with a money back guarantee, as shown in the advertisement below.

After reading the advertisement, you decide to arrange for your parcel to be delivered by ABC Express, at the cost of $£ 40.00$. The price is more expensive than you usually pay for parcel delivery, but you are ready to incur this cost, as you want a next day delivery.

You decide to phone ABC Express to arrange for the delivery and confirm the time your parcel is scheduled to arrive at your parents' house. When you call, the employee confirms that your parcel will be delivered the next working day between 9am and 1pm. You are also told that you will be able to track the status of your delivery through an online tracking system. However, your parents do not

Service failure receive the parcel by $1 \mathrm{pm}$ the next day. Therefore you check the status of your delivery online. The online tracking system shows that your parcel is at the depot. Now you are sure that the parcel has not been delivered and you call ABC Express customer service team to complain.

\begin{tabular}{|c|c|c|c|}
\hline & High & Medium & Low \\
\hline Payout & $\begin{array}{l}\text { "As part of our guarantee, we will } \\
\text { provide you with a refund of the } \\
\text { delivery charges incurred and we will } \\
\text { attempt to re-deliver the parcel as soon } \\
\text { as possible, free of charge. In addition, } \\
\text { we will offer you a } 25 \% \text { discount on } \\
\text { your next purchase". }\end{array}$ & $\begin{array}{l}\text { "As part of our guarantee, we will } \\
\text { provide you with a refund of the } \\
\text { delivery charges incurred and we will } \\
\text { attempt to re-deliver the parcel as soon } \\
\text { as possible, free of charge." }\end{array}$ & $\begin{array}{l}\text { "We will try to re-deliver the parcel as soon as } \\
\text { possible, free of charge. However, we cannot } \\
\text { refund your delivery charges as we attempted to } \\
\text { deliver the parcel the next day but the postcode } \\
\text { could not be found. The parcel is now at our } \\
\text { depot. We will offer you a } 10 \% \text { discount on your } \\
\text { next purchase." }\end{array}$ \\
\hline EoI & $\begin{array}{l}\text { "To claim the guarantee, no questions } \\
\text { will be asked. You will need to fill in a } \\
\text { short online claim form with your } \\
\text { details within the next three working } \\
\text { days." }\end{array}$ & $\begin{array}{l}\text { "To claim the guarantee, you will need } \\
\text { to fill in and email us a claim form } \\
\text { within three working days. In the claim } \\
\text { form, you will need to provide details of } \\
\text { what went wrong." }\end{array}$ & $\begin{array}{l}\text { "To claim the guarantee, you will need to fill in } \\
\text { and mail a claim form within three working days } \\
\text { from the scheduled delivery date. In the claim } \\
\text { form, you will need to explain what went wrong, } \\
\text { enclose a proof of purchase and mail the } \\
\text { documentation to our Customer Relations Team, } \\
\text { who will carry out a validity check of your claim. }\end{array}$ \\
\hline
\end{tabular}


Appendix 3

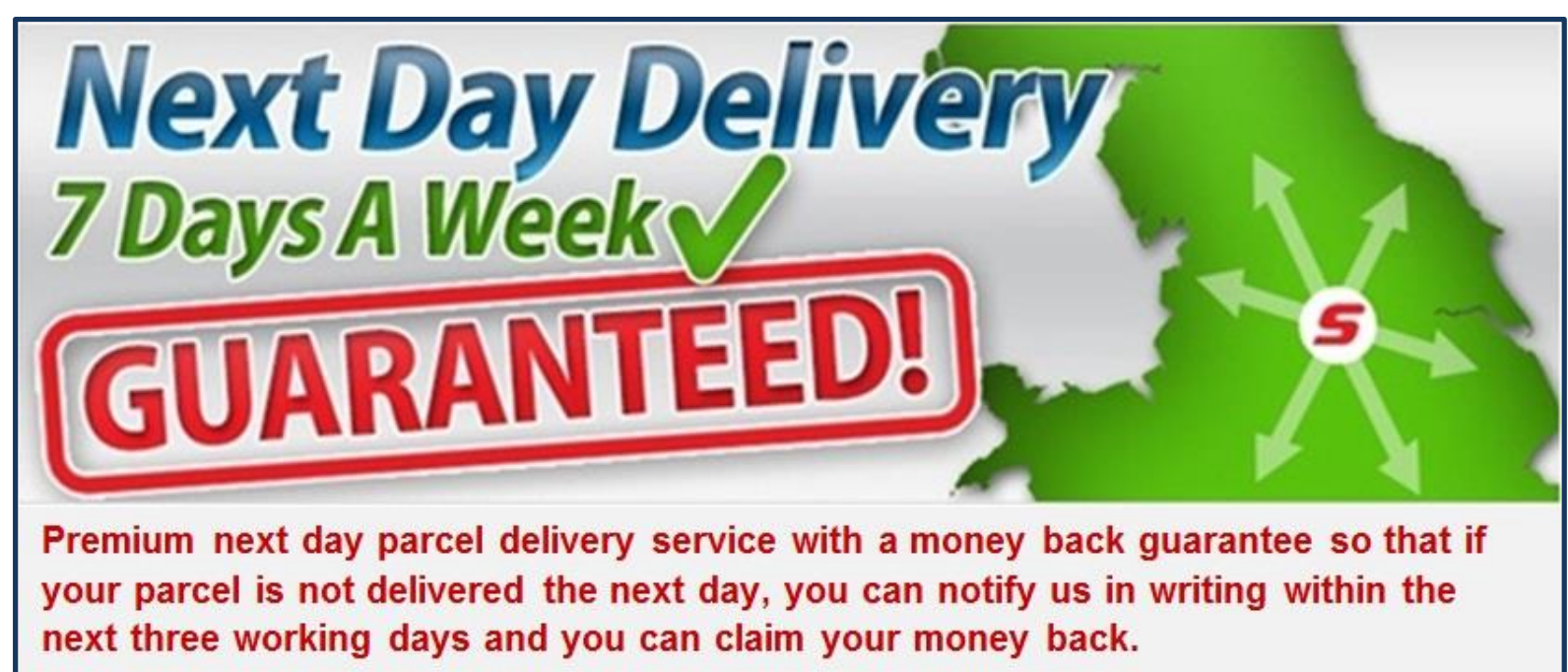




\section{Author Details}

Benedetta Crisafulli is a Lecturer in Marketing at Cranfield School of Management, Cranfield University (UK). She recently completed her PhD studies at Kingston Business School, Kingston University London. Benedetta's research interests are in consumer behaviour and services marketing, focusing on consumer psychological processes during service failure and recovery encounters. Benedetta has published in the Journal of Service Theory and Practice, a chapter in a specialist book on services marketing published by Springer, and has presented her work at several international conferences.

Dr Jaywant Singh is Associate Professor in Marketing at Kingston Business School, Kingston University London (UK). His research interests are in the areas of consumer behaviour, branding and services marketing. He has published in, amongst others, the Journal of Business Research, Marketing Letters, Journal of Advertising Research, Journal of Business Ethics, European Journal of Marketing, Industrial Marketing Management, Journal of Service Theory and Practice, and International Journal of Market Research. 